\title{
Erratum to: Stability and efficiency of supported liquid membranes in electromembrane extraction-a link to solvent properties
}

\author{
Knut Fredrik Seip • Moheba Faizi • Cristina Vergel • \\ Astrid Gjelstad • Stig Pedersen-Bjergaard
}

Received: 11 December 2013 / Accepted: 11 December 2013 / Published online: 24 December 2013

(C) Springer-Verlag Berlin Heidelberg 2013

\section{Erratum to: Analytical and Bioanalytical Chemistry}

DOI 10.1007/s00216-013-7418-8

Unfortunately there was a mistake in Cristina Vergel's affiliation.

The correct affiliation for Cristina Vergel is

Department of Analytical Chemistry,

Faculty of Marine and Environmental Sciences,

University of Cádiz,

11510 Puerto Real (Cádiz), Spain

Published in the topical collection Microextraction Techniques with guest editors Miguel Valcárcel Cases, Soledad Cárdenas Aranzana and Rafael Lucena Rodríguez.

The online version of the original article can be found at http://dx.doi.org/ 10.1007/s00216-013-7418-8.

K. F. Seip · M. Faizi $\cdot$ A. Gjelstad $\cdot$ S. Pedersen-Bjergaard $(\bowtie)$

School of Pharmacy, University of Oslo, P.O. Box 1068 Blindern,

0316 Oslo, Norway

e-mail: stig.pedersen-bjergaard@farmasi.uio.no

S. Pedersen-Bjergaard

Department of Pharmacy, Faculty of Health and Medical Sciences,

University of Copenhagen, 2100 Copenhagen, Denmark

C. Vergel

Department of Analytical Chemistry, Faculty of Marine and Environmental Sciences, University of Cádiz, 11510 Puerto Real

(Cádiz), Spain 